\title{
Effect of fluid viscosity on asphalthene deposition rate during turbulent flow in oil wells
}

\author{
Gholamreza Vakili-Nezhaad $^{1,}$, , Nabeel Al-Rawahi ${ }^{2}$, G. Ali Mansoori ${ }^{3}$, Amin Fatemi $^{4}$ \\ ${ }^{1}$ Department of Petroleum \& Chemical Engineering, College of Engineering, Sultan Qaboos University, Muscat, Oman \\ ${ }^{2}$ Department of Mechanical \& Industrial Engineering, College of Engineering, Sultan Qaboos University, Muscat, Oman \\ ${ }^{3}$ Depts of Bioengineering, Chemical Engineering and Physics, University of Illinois at Chicago, Chicago, IL, USA \\ ${ }^{4}$ Department of Geotechnology, Faculty of Civil Engineering and Geosciences, Delft University of Technology, Delft, Netherlands
}

\section{Email address:}

Vakili@squ.edu.om(G. Vakili-Nezhaad), alrawahi@squ.edu.om(N. Al-Rawahi),mansoori@uic.edu(G. A. Mansoori), s.a.fatemi@tudelft.nl(A. Fatemi)

\section{To cite this article:}

Gholamreza Vakili-Nezhaad, Nabeel Al-Rawahi, G. Ali Mansoori, Amin Fatemi. Effect of Fluid Viscosity on Asphalthene Deposition Rate during Turbulent Flow in Oil Wells. American Journal of Chemical Engineering. Vol. 1, No. 2, 2013, pp. 45-49.

doi: $10.11648 /$ j.ajche.20130102.13

\begin{abstract}
The production and transportation of petroleum fluids will be severely affected by the deposition of suspended particles (i.e. asphaltenes, diamondoids, paraffin/wax, sand, etc.) in petroleum fluid production wells and/or transfer pipelines. Viscosity variations of petroleum fluid are an important phenomenon that could have significant effect on different properties related to petroleum fluid. Therefore, it is important to understand the effect of viscosity variations of petroleum fluid onthe deposition rate of suspended particles on the walls of the flowing channel. In this study, the analytical model for the prefouling behavior of suspended particles in production lines ischallenged in terms of viscosity changes that occur during the production in oil wells/tubings fora typical fluid sample experiencing particle deposition. Calculations of particle deposition rate inoil wells/tubings considering the change in viscosity for this typical oil sample is taken into consideration. The analysis presented in this report shows that rates of particle deposition (during petroleum fluid production) on the walls of the oil well/tubing is slightly effected by the viscosity variations that occur during the production conditions and it is also shown that the assumption of constant viscosity while deriving the analytical model for the deposition rate of particles on the walls of fluid conduits is quite a reasonable and valid assumption.
\end{abstract}

Keywords: Asphalthene, Deposition, Turbulent Flow, Viscosity, Oil Wells

\section{Introduction}

An oil mixture is assumed to be a complex polydisperse mixture such as light and heavy paraffins, aromatics, resins and asphaltenes. Asphaltene can be defined as the fraction of crude oil that is insoluble in normal alkanes but soluble in toluene and benzene [1]. Asphaltene is recognized as the heavy fraction of petroleum mixture, which is insoluble in some species such as paraffins but soluble in others such as aromatics (benzene, toluene, etc.) [2]. The liquid state of oil is the results of the equilibrium of these components in the liquid and vapor phases. Change in some of the environmental parameters, such as pressure and composition, can change stable condition in an oil mixture to some other condition in which the oil mixture will be unstable and finally heavy organics, such as asphaltenes or waxes flocculate and deposit [3,10]. Asphaltene precipitation is animportant and serious problem with which the oil industry has encountered for a long time $[1,11,12,13]$. Suspended asphaltenic heavy organic particles in petroleum fluids may stick to the inner walls of oil wells and pipelines and this is the major reason for fouling and arterial blockage in the petroleum industry. Phase behavior, viscosity and interface properties of crude oil are strongly influenced by asphaltene components $[1,9,14]$. The study of the behavior of suspended heavyorganic particles during flow conditions has been focused on the production well and an analysis of the effect of viscosity variations on the deposition rate of heavy particles has been taken into consideration. This study considers variations of viscosity in a typical reservoir fluid due to pressure change and how it could affect the overall deposition rate. The goal of this study is to find out whether 
the viscosity variations caused by pressure change in the crude oil under production is significant enough to have a major effect on the overall deposition rate coefficient on the walls of the production well.

\section{Theoretical Analysis}

The analysis in this study relies on the work done in[1] which has derived the analytical model for rate of heavy particle deposition on the walls of production wells in turbulent flow. The theoretical analysis presented in [1] is done for a system of constant density and viscosity. This assumption makes the analysis applicable to one-phase region above the bubble point where only the liquid is present. The assumptions of constant viscosity and constant density could be partially justified since density changes are not appreciable until the bubble point pressure is reached inside the well. The main objective is to study the behavior of a typical crude oil experiencing heavy particle deposition during production operations and find out how the variation of viscosity due to pressure changes could affect the overall deposition rate of heavy particles on the walls of the production well.

\section{Experimental Data and Fluid Characteristics}

The representative single-phase bottom-hole sample used in this work has been collected from aMexican reservoir (light crude oil from the Southeast region of Mexico), which has a serious asphaltene deposition problem during its primary production stage [4]. Table 1 shows properties of the oil sample.

Table 1.Oil sample characteristics at reservoir temperature [4]

\begin{tabular}{cc}
\hline Property & Value \\
\hline P (Saturation) & $45 \mathrm{MPa}$ \\
P (Onset) & N/A \\
GOR & $365\left(\mathrm{~m}^{3} / \mathrm{m}^{3}\right)$ \\
Heavy Particles & $2.7 \mathrm{wt} \%$ \\
API & 34 \\
$v \times 10^{6}$ & $6.7 \mathrm{~m}^{2}$ \\
Density & $833 \mathrm{~kg} / \mathrm{m}^{3}$ \\
\hline
\end{tabular}

Reservoir temperature and pressure conditions of a single-phase bottom-hole sample have been reproduced in laboratory in order to get the best possible and most representative sample using a bulk apparatus with details of the apparatus and laboratory experiment well demonstrated [4]. To determine the viscosity behavior of the reservoir fluid, at the study temperature and different pressures, a constant forced electromagnetic viscometer has been used [4]. The onset of asphaltene precipitation as well as the bubble point pressure curve of the reservoir fluid has been identified to be as fig. 1 .

Due to conditions of an oil well, particle deposition and precipitation are considered to happen simultaneously in the oil well and therefore fig. 1 could be a representative of what a reservoir fluid undergoes when entering the oil well to the point where the single-phase region of the oil well ends, correspondent to the point where pressure of the reservoir fluid falls below the bubble point pressure. The illustration of different flow regimes in an oil well is presented in fig. 2, in which, the area of main interest is well demonstrated. In this region of the wellbore, there is a single-phase fluid flow and major problem of blockage is considered to be in this zone of the wellbore.

\section{Modeling and Calculations}

From data of fig. 1, it is observed that the data fall on a straight line with a slope of $0.0022 \mathrm{Cp}$ per $M P a$ of pressure drop as depicted in fig. 3.The trend follows a linear relationship with the slope of viscosity variation of the crude oil to be so small compared to the unit pressure drop across the pipe. Considering the variation of the viscosity

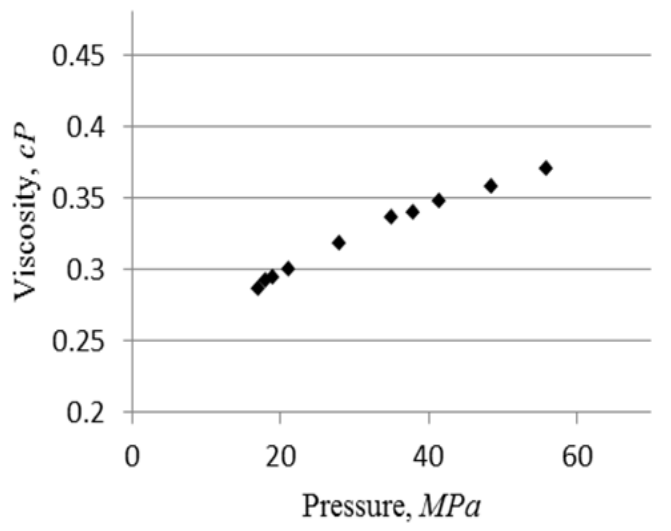

Figure1. Viscosity isotherm of the live crude oil from reservoir pressure to bubble-point pressure at reservoir temperature

for the specified pressure range and using the experimental Data of Friedlander [2] and Beal [5], and assuming a typical value for the average radius of the particles, the rate of deposition of asphalting particles on oil well walls has been calculated. Expression used for deposition rate coefficient calculation is [1]:

$$
K=V_{\text {avg }} \sqrt{f / 2}\left\{\frac{11.15^{3} \varphi^{2}}{3} F 1-\frac{11.15^{3} \varphi^{2}}{1.5 D i^{8}}+11.4 \theta F 3+F 5\right\}^{-1}
$$

Where $V_{a v g}$ is the average velocity of fluid in the well, $f$ is the pipe friction factor and $D_{\mathrm{i}}{ }^{*}$ is the dimensionless inner well diameter. Parameters $F_{1}, F_{2}, F_{3}, F_{5}, \theta$, and $\varphi$ in this equation are defined as follows $[1,9]$ :

$$
\begin{aligned}
& F_{1}=\frac{1}{2} \ln \left[\frac{(1+5 \phi)^{2}}{(1-5 \phi)^{2}}\right]-\frac{1}{2} \ln \left[\frac{\left(1+S_{\mathrm{d}}^{*} \phi\right)^{2}}{\left(1-S_{\mathrm{d}}^{*} \phi\right)^{2}}\right]+ \\
& \sqrt{3} \tan ^{-1}\left(\frac{10 \phi-1}{\sqrt{3}}\right)-\sqrt{3} \tan ^{-1}\left(\frac{2 S_{\mathrm{d}}^{*} \phi-1}{\sqrt{3}}\right)
\end{aligned}
$$




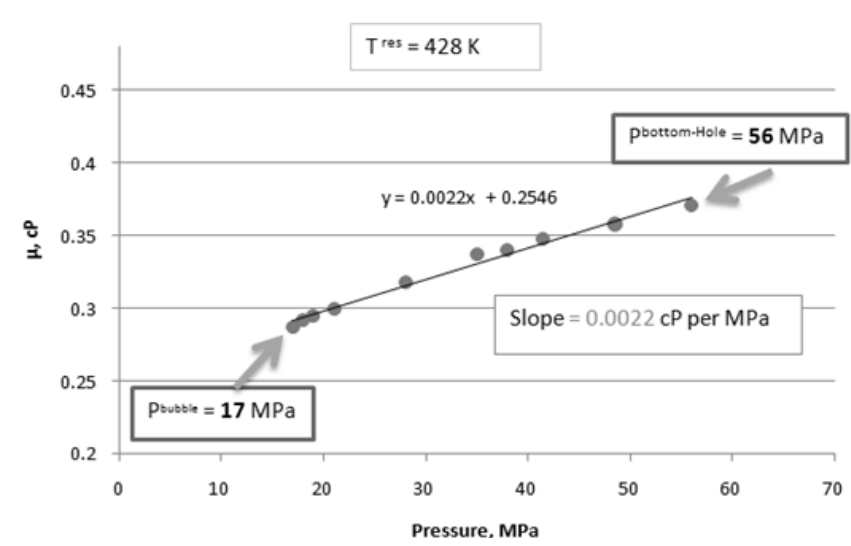

Figure 3. Analysis of viscosity isotherm of the live crude oil

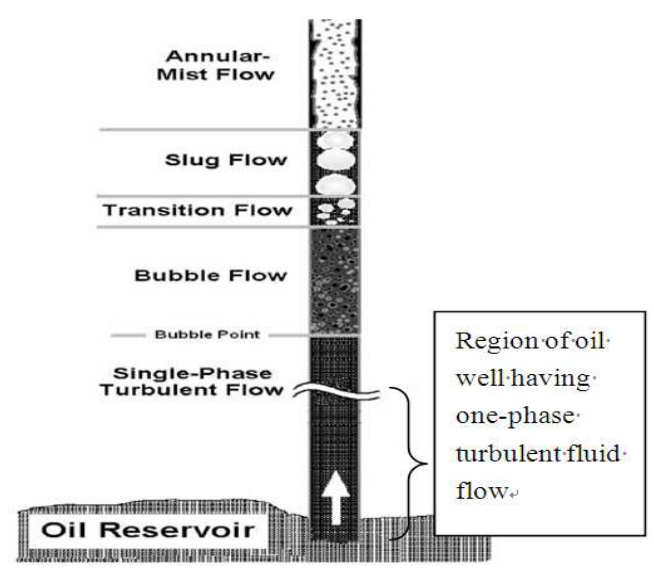

Figure 2. Illustration of different flow regimes in single-phase turbulent flow condition in the oil well[1].

$$
\begin{array}{r}
F_{2}=\frac{1}{2} \ln \left[\frac{(1-5 \phi)^{2}}{(1+5 \phi)^{2}}\right]-\frac{1}{2} \ln \left[\frac{\left(1-S_{\mathrm{d}}^{*} \phi\right)^{2}}{\left(1+S_{\mathrm{d}}^{*} \phi\right)^{2}}\right]+ \\
\sqrt{3} \tan ^{-1}\left(\frac{10 \phi-1}{\sqrt{3}}\right)-\sqrt{3} \tan ^{-1}\left(\frac{2 S_{\mathrm{d}}^{*} \phi-1}{\sqrt{3}}\right) \\
F_{3}=\frac{1}{2} \ln \left[\frac{11.4-30 \theta}{11.4+30 \theta}\right]-\frac{1}{2} \ln \left[\frac{11.4-5 \theta}{11.4+5 \theta}\right] \\
F_{5}=-\frac{11.4^{2}}{D_{\mathrm{i}}^{*}} \ln \left[\frac{11.4^{2}-(30 \theta)^{2}}{11.4^{2}-(5 \theta)^{2}}\right]+ \\
\left(2.5+\frac{12.5}{D_{\mathrm{i}}^{*} 11.15^{2} \phi^{2}}\right) \ln \left[\frac{1+0.4\left(11.15^{2}\right) r_{\text {avg }}^{*} \phi^{2}}{1+12\left(11.15^{2}\right) \phi^{2}}\right]+\frac{150-5 r_{\text {avg }}^{*}}{D_{\mathrm{i}}^{*}} \\
\theta \equiv\left[\frac{N_{\text {Sch }}}{\left(0.1923 \cdot N_{\text {Sch }}-1\right)}\right]^{1 / 2} \\
\varnothing \equiv \frac{\mathrm{Nsch}^{1 / 3}}{11.15}
\end{array}
$$

In above equation $N_{\text {sch }}$ is the Schmidt number defined as: $\mathrm{Nsch} \equiv \frac{\gamma}{\mathrm{D}^{\mathrm{B}}}(8)$

Parameters $S d^{*}$ is the dimensionless stopping distance defined as follows:

$$
S_{\mathrm{d}}^{*}=S_{\mathrm{d}}\left[\frac{V_{\text {avg }} \sqrt{f / 2}}{v}\right]
$$
[6]:

Pipe friction factor for smooth pipes is also defined as

$$
f=0.3164 / R e^{0.25}
$$

For the calculations, a set of assumption have been made, like the suspended particles are all the same diameter and that particle-particle interactions between them are ignorable $[1,7,8]$.

Using above expressions and considering experimental values for all the variables appearing in above expressions, a MATLAB computer code was developed to calculate the effect of viscosity variation on deposition rate coefficient. The calculation procedure implemented is mentioned here step by step:

1- Inputs of the program are:

- Reservoir Temperature

- Typical particle diameter

- Oil sample characteristics from table 1

- Average velocity of fluid in pipe

- Typical inner well diameter

- friction factor

2- Using two viscosities (once for the crude at reservoir pressure and once for the crude is at bubble point pressure), Reynolds number is measured according to various fluid average velocities and using expressions 1 to 8 the rate of deposition coefficient of heavy particles is computed.

3- Outputs are the values of rate of deposition at two mentioned viscosities versus the different Reynolds numbers.

\section{Results and Discussion}

Table 2 shows results of calculations for the deposition rate coefficient at two different viscosities, first column the viscosity of the fluid at reservoir pressure and second column the viscosity of the fluid at bubble point pressure which is equivalent to the pressure of the crude oil leaving the single phase region of the wellbore.

Table 2. Calculation of deposition rate coefficient at different Reynolds number with different viscosities, $\mu_{1}$ is the viscosity of oil at reservoir pressure, $\mu_{2}$ is the viscosity of oil at bubble point pressure

\begin{tabular}{ccc}
\hline $\mathbf{R e}$ & $\mathbf{k} @ \boldsymbol{\mu}_{\mathbf{1}}$ & $\mathbf{k} @ \boldsymbol{\mu}_{2}$ \\
\hline 7450 & 0.1648 & 0.1725 \\
9700 & 2.6603 & 2.7701 \\
9700 & 2.1532 & 2.2111 \\
7450 & 1.5512 & 1.6104 \\
11900 & 5.5123 & 5.6276 \\
11900 & 6.4932 & 6.5588 \\
11900 & 22.0132 & 22.1523 \\
11900 & 33.10123 & 33.3002 \\
3000 & 41.5023 & 41.7643 \\
\hline
\end{tabular}




\begin{tabular}{ccc}
\hline 4800 & 56.0765 & 56.1923 \\
11950 & 61.10139 & 61.9027 \\
6950 & 85.1092 & 85.7882 \\
14600 & 390.8889 & 391.888 \\
\hline
\end{tabular}

Fig. 4 depicts this comparison. Presenting data of table 2 on a single graph makes it possible to make a good comparison between the variations caused in the deposition rate coefficient calculations.

Overlap of depostion rate coefficient data

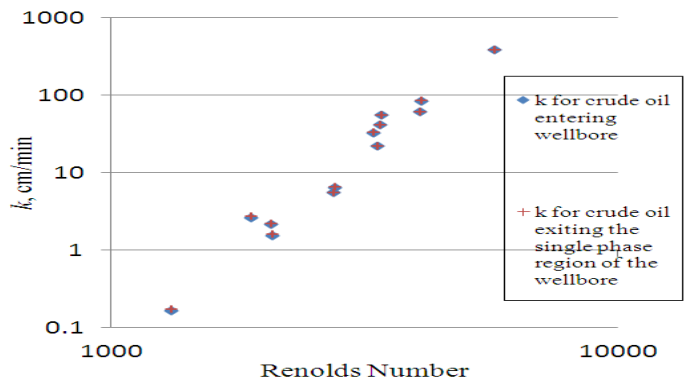

Figure 4. Deposition rate coefficient data at two different viscosities according to table 1

The relative error percent of the tabulated data have been compared through the following well known expression:

$$
\text { Relative error }=\left(k^{\text {new }}-k / k\right) \times 100
$$

Using the above expression, the following table for the relative error percent is obtained, which shows to what extent the deposition rate coefficient has been altered by the viscosity.

Table 3. Relative error percent of deposition rate coefficient calculations at two different viscosities

\begin{tabular}{cc}
\hline $\boldsymbol{R e}$ & Error \% \\
\hline 7450 & 4.672330097 \\
9700 & 4.127354058 \\
9700 & 2.689020992 \\
7450 & 3.816400206 \\
11900 & 2.091685866 \\
11900 & 1.010287686 \\
11900 & 0.631893591 \\
11900 & 0.601095488 \\
3000 & 0.631290314 \\
4800 & 0.206503616 \\
11950 & 1.31144316 \\
6950 & 0.797798593 \\
14600 & 0.255596923 \\
\hline
\end{tabular}

Showing data of table 2 on a bar graph could depict a better comparison between the calculated values of the deposition rate coefficients at two different viscosities of the crude entering the wellbore and the crude exiting the single-phase region of the wellbore as in fig. 5 .

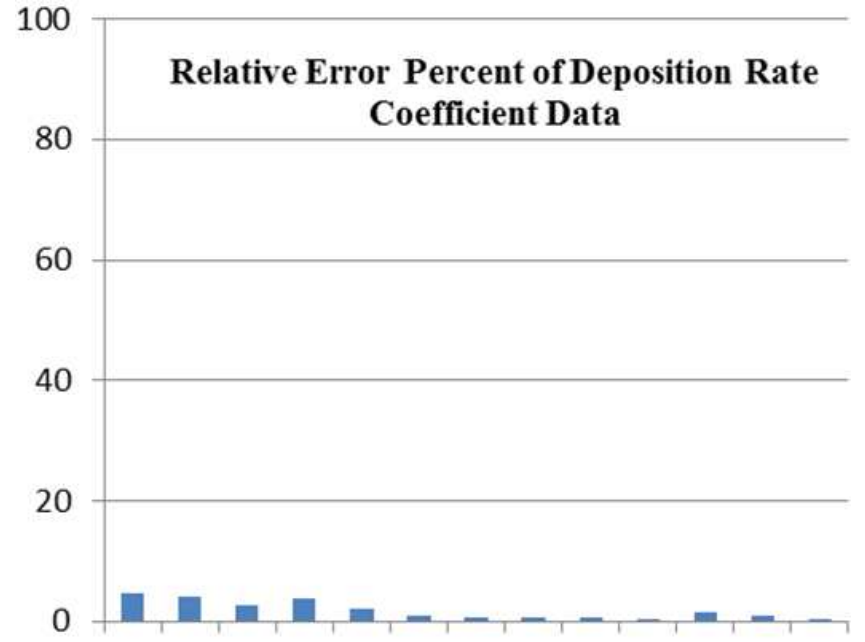

Figure 5. Bar Graph representation of relative error percent of deposition rate coefficient calculations

As can be seen in fig. 5, contribution of change in viscosity leads to literally ignorable variation on asphaltene deposition of a single phase flow of a typical real oil sample data.

\section{Conclusion}

As can be seen from table 2, although we have implemented the maximum possible amount of the viscosity variation for the calculation of deposition rate coefficient, the amount of error percent appearing in the calculations seems to be so insignificant that causes a very small change in the final result of the calculations.

Variation of the viscosity itself in the whole single-phase region of the oil well is so small that when contributing to the overall deposition rate coefficient, it would have a negligible effect on our calculations. Relative error percent of deposition rate coefficient calculations according to the variation in viscosity has been well demonstrated in fig.5 as a bar graph.

Therefore, it can be well assumed that the viscosity for the single-phase region of the oil well is a constant value and calculations of deposition rate coefficient based on this assumption fall within an acceptable accuracy.

\section{Acknowledgments}

The research leading to these results has received funding from Petroleum Development Oman (PDO), through research agreement no. CTR\#2009/111.

\section{Nomenclature}

$P=$ Pressure $(P a)$

$G O R=$ Gas oil ratio $\left(\mathrm{m}^{3} / \mathrm{m}^{3}\right)$

$v=$ Velocity $\left(\mathrm{m}^{2}\right)$

$V_{a v g}=$ Average velocity of fluid in the well, $m^{2}$

$\mu=$ Density $\left(\mathrm{kg} / \mathrm{m}^{3}\right)$ 
$k=$ asphaltene deposition rate $(\mathrm{cm} / \mathrm{min})$

$R E=$ Reynolds Number

$f=$ Pipe friction factor

$D_{\mathrm{i}}{ }^{*}=$ Dimensionless inner well diameter

$N_{\text {sch }}=$ Schmidt number

$S d^{*}=$ Dimensionless stopping distance

\section{References}

[1] Escobedo J. and G.A. Mansoori, "Prefouling Behavior of Suspended Particles in Petroleum Fluid Flow", SCINTIA IRANICA, Vol. 17, No. 1, 77-85 (2010).

[2] Escobedo, J. and Mansoori, G.A. "Asphaltene and other heavy-organic particle deposition during transfer and production operations", SPE paper \#30672, Proceed. Soc. of Petrol Eng. Annual. Tech. Conf. Held in Dallas, TX (22-25 Oct. 1995).

[3] Vafaie-Sefti, M. Mousavi-Dehghani, S.A., Riazi, M.R., and Mansoori, G.A. "An analysis of methods for determination of onsets of asphaltene phase separations", J. Petrol Sci. \& Eng., 42(2-4), pp. 145-156 (2004).

[4] José L. Mendoza de la Cruz, Francisco J. Argu $\square$ elles-Vivas, Víctor Matías-Pérez, Cecilia de los A. Durán-Valencia and Simón López-Ramírez,"Asphaltene-Induced Precipitation and Deposition During Pressure Depletion on a Porous Medium: An Experimental Investigation and Modeling Approach", Energy \& Fuels 23 (2009), 5611-5625.

[5] Friedlander, S.K. and Johnstone, H.F. "Deposition of suspended particles from turbulent gas streams", Ind. Eng. Chem., 49 (7), pp. 1151-1156, 1957.

[6] M. Jamialahmadi, B. Soltani, H. Müller-Steinhagen, D. Rashtchian, "Measurement and prediction of the rate of deposition of flocculated asphaltene particles from oil",
International Journal of Heat and Mass Transfer Volume 52, Issues 19-20, September 2009,4624-4634.

[7] Beal, S.K. "Deposition of particles in turbulent flow on channel or pipe walls", Nuclear Sci. Eng., 40, pp. 1-11 (1970).

[8] Lauufer, J. "The Structure of turbulence in fully developed pipe flow", NACA 1174, National Advisory Committee for Aeronautics (Available from NASA as TR-1174) (1954).

[9] J. Escobedo, G.A. Mansoori, C. Balderas-Joers, L.J. Carranza-Becerra, M.A. Mendez-Garcia, Heavy Organic Deposition During Oil Production from a Hot Deep Reservoir: A Field Experience, SPE Paper \#38989 (9), Proceedings of the $5^{\text {th }}$ Latin American and Caribbean Petroleum Engineering Conference and Exhibition, Rio de Janeiro, Brazil, 30 August-3 September 1997.

[10] Colebrook, C.F., 1939. Turbulent flow in pipes with particular reference to the transition region between the smooth and rough pipes laws. J. Inst. Civil Eng. 11, 133156.

[11] Dos Santos, J.S.T., Fernandes, A.C., Giulietti, M., 2004. Study of the paraffin deposit formation using the cold finger methodology for Brazilian crude oils. J. Pet. Sci. Eng. 45 (1-2), 47-60 (30 November).

[12] Zougari M., Hammami A., Broze G. and Fuex N. Live oils novel organic solid deposition and control device: wax deposition validation, SPE Special Edition, 99538, 2005.

[13] Zougari, M., Jacobs, S., Hammami, A., Broze, G., Flannery, M., Ratulowski, J., Stankiewicz, A., Novel organic solid deposition and control device for live oils: design and applications. Energy \& Fuels 20 (2006), 1656-1663.

[14] Zougari, M. Shear driven crude oil wax deposition evaluation, Journal of Petroleum Science and Engineering 70 (2010) 28-34. 